\title{
LEVERAGING SPORT EVENTS TO MAXIMIZE COMMUNITY BENEFITS IN LOW- AND MIDDLE-INCOME COUNTRIES
}

\author{
NICO SCHULENKORF AND KATIE SCHLENKER
}

University of Technology Sydney, Ultimo, NSW, Australia

\begin{abstract}
For many years, special events have played an important role as strategic elements within community development. However, to date little work has been conducted on how to maximize the social potential of special events in low- and middle-income countries. In addressing this issue, we reflect on event management processes and leverage mechanisms that have underpinned a community sport event in the Pacific Island nation of Sāmoa, and identify strategies for maximizing beneficial event outcomes. We present findings related to previously identified leverage areas, including sociocultural and participatory leverage, and also suggest new areas that seem particularly relevant in the context of community development, including educational, health-related, and reputational leverage. Finally, key challenges and opportunities for event managers and local communities are discussed, implications for event leverage are provided, and areas for future research are outlined.
\end{abstract}

\section{Key words: Special events; Sport event leverage; Community development;} Pacific Islands; Sāmoa

Introduction

Sport events can hold a significant role in the lives of people and their communities. By providing a forum for socialization, entertainment, and engagement, sport events present opportunities for people from all over the world to play, attend, watch, listen to, talk about, experience, and even feel sport at all levels of performance (Schulenkorf, 2010). In contrast to large-scale or mega-events, community sport events are typically organized by the community for the community; they can be described as "themed public occasions designed to occur for a limited duration that celebrate valued aspects of a community's way of life" (Dimmock \& Tiyce, 2001, p. 358).

For many years, special events have played an important role as strategic elements within wider community development efforts. Given the temporal nature and infrequent occurrence of special events, researchers have increasingly investigated opportunities to sustain benefits beyond the duration of the event itself. Moreover, importance has been placed on identifying mechanisms toward 
growing and spreading positive event outcomes beyond the festival ground, to impact not only participants and spectators, but also event stakeholders and the wider community (Schulenkorf \& Edwards, 2012). However, to date, little work has been conducted on how to maximize the potential of special events in low- and middle-income countries (LMICs). In addressing this issue, we reflect on event management processes and mechanisms that have underpinned a community sport event in the Pacific Island nation of Sāmoa. In short, the purpose of our study is to provide an empirical investigation of a small-scale community event and contribute to the limited body of literature on how to maximize beneficial outcomes of sport events for host communities in LMICs. Findings will be of significant importance for event planners, managers, and scholars who set out to use events as strategic vehicles for achieving wider community development goals.

\section{Literature Review}

Much attention in the sport event literature has been given to recognizing the direct and indirect impacts and outcomes a sport event can have on its host community. General classifications suggest that sport events can have economic, tourism, sociocultural, physical, political, and psychological impacts (Brown \& Massey, 2001; Preuss \& Solberg, 2006; Ritchie, 1984). However, as Chalip (2004) argued, "it is no longer suitable merely to host an event in the hope that desired outcomes will be achieved; it is necessary to form and implement strategies and tactics that capitalize fully on the opportunities each event affords” (p. 245). Such a strategic approach, which includes planning how host communities can maximize the potential benefits from sport events, is known as event leverage (Chalip, 2004; O’Brien \& Chalip, 2008). Importantly, studies of event leverage shift the focus from measuring event impacts and outcomes to a focus on the processes and mechanisms used to increase the chances of realizing desired outcomes (Chalip, 2006; O’Brien \& Chalip, 2007, 2008; Ziakas, 2014). With this in mind, the concept of event leverage provides the theoretical underpinning for our empirical study of employing special events as strategic vehicles for generating beneficial community development outcomes.
In explaining the concept of event leverage, O’Brien (2006) described events as "seed capital" that can be used as a springboard for delivering longer-term benefits to a host community. Although there are potentially a wide range of areas for which event leverage strategies can be used, it is the economic, business, and tourism impacts that have dominated researcher attention. Leverage strategies for economic and tourism purposes include increasing repeat visitation to host regions, fostering long-term business relationships, and encouraging employment, trade, and investment into the host destination (Chalip \& Leyns, 2002; Chalip \& McGuirty, 2004; O’Brien, 2006). The predominant focus on such tangible outcomes of sport events can be understood in conjunction with the fact that much of the sport event leverage research takes place in the context of governmentsupported large-scale or mega-events. Here, research contributes to providing an evidence base to justify the vast investment of taxpayer money often associated with the staging of spectacles such as international championships, World Cups, or Olympic Games (Karadakis, Kaplanidou, \& Karlis, 2010; Schulenkorf, Schlenker, \& Thomson, 2017).

More recently, researchers have begun to give due attention to leveraging events for a wider range of intangible and "soft" impacts. In particular, studies on social and cultural leveraging have emerged, painting the picture of a more complex field of research that relates to the potential for sport events to contribute to a wide variety of societal benefits, including community connectedness and pride, social capital and community building, physical activity, and sport participation (Craig \& Bauman, 2014; Misener \& Mason, 2006, 2008; Misener, McGillivray, Gayle, \& Legg, 2015; Schulenkorf, 2013; Smith, 2009; Taks, Green, Misener, \& Chalip, 2014; Taks, Misener, Chalip, \& Green., 2013; Weed, Coren, \& Fiore, 2009). In his groundbreaking work on social leverage, Chalip (2006) pointed to the celebratory nature of sports events and the "sense of importance" that can create "liminoid spaces" through which community spirit and social values can be promoted. Leveraging strategies, such as facilitating social contact through designing open and safe spaces and providing informal social opportunities, can therefore be useful approaches towards maximizing an event's social potential 
(Spaaij \& Schulenkorf, 2014; Welty Peachey, Borland, Lobpries, \& Cohen, 2015). At the same time, using event-related festivities to enhance the celebratory atmosphere serves to both attract a larger audience and draw nonattendees into the event sphere (Schulenkorf et al., 2017).

Although a large portion of the sport event leverage literature focuses on the outcomes of large-scale and mega-events, there has been a growing number of studies focused on maximizing the outcomes of smaller scale or community events (Schulenkorf \& Edwards, 2012; Taks, 2013; Welty Peachey et al., 2015). Misener (2015) suggested that, in fact, smaller events have greater potential for leveraging social issues than do large-scale events or megaevents. Firstly, small-scale events lack the large capital expenditure and financial risks associated with mega-events, meaning the focus for leveraging strategies need not be prioritized around justifying large financial investments (Smith, 2012). Secondly, with smaller scale events there is "the potential for tighter social networks and connectedness of the local population with the event, be it as politicians, spectators, volunteers, marketing destination managers, or event organizers" (Misener, Taks, Chalip, \& Green, 2015, p. 4). By utilizing local infrastructure and building on community resources, small-scale or community events are more likely to maximize the direct benefits for their host communities than a mega-event might (Smith, 2012; Ziakas, 2015).

Thus, in the context of the current research, of particular interest are the growing number of studies on small-scale, regional, or national events that reveal a greater concern for leveraging community sport events in the context of social disadvantage. This may include social issues such as physical inactivity, ill health, or promoting awareness of homelessness and disability (Derom \& VanWynsberghe, 2015; Lane, Murphy, \& Bauman, 2013; Misener, 2015; O’Brien, 2007; Schulenkorf \& Edwards, 2012; Welty Peachey et al., 2015). For example, resulting from her research on smallmedium scale parasport events, Misener (2015) developed the parasport-leveraging framework as a basis for developing leveraging strategies that provide greater levels of accessibility and enhanced opportunities for people with a disability to participate in community life. Considered key to the parasport-leveraging framework-and, therefore, to developing leveraging strategies-are a number of interrelated factors, including the broader policy environment, the local community as central to the leveraging efforts, a community champion or catalyst, a leveraging subcommittee distinct from that concerned with organizing the event, and targeted and measurable goals for leverage. Misener (2015) also argued that the community affected by the event should be central to any leveraging efforts, and particularly that its needs, interests, and values should be at the core of leveraging strategies. In line with previous empirical work on sport event leverage in disadvantaged community settings (see Schulenkorf \& Edwards, 2012; Welty Peachey et al., 2015), this argument is of particular importance for the current study that investigates a community sport event in the Pacific Islands that aims to develop local capacities by taking into account important social and cultural norms and the values of the local Sāmoan population.

In a recent study on leveraging a community event for increased physical activity, Lane et al. (2013) examined a women's minimarathon in Ireland. Participants were recruited from over 50,000 women who had taken part in either of two mass community walk/run events, who were then separated into "intervention" and control groups. The strategy used to leverage the event for increased physical activity was the specific, targeted, and augmented communication of information to the target group. While those in the control group received only a healthy eating leaflet, the intervention group received a mixture of information on community resources, the promotion of walking, and training groups and exercise classes, as well as the provision of training plans and physical activity diaries. Both groups reported an increase in physical activity, though this was more significantly pronounced in the intervention group. The authors stressed that targeted communication and community engagement are critical to the success of leveraging attempts, and that the more types of intervention people received, the better the result. Moreover, they argued that unlike one-off events like the Olympic Games, annual small-scale events appear better equipped in the long run to encourage physical activity, as they act as regular reminders of the health benefits of physical activity and are more integrated into the community. 
Derom and VanWynsberghe (2015) conducted another investigation into sport event leveraging for increased participation in physical activity. This study involved a cycling event, the Tour of Flanders in the Netherlands, and examined leveraging initiatives designed to increase physical activity and health benefits specifically for local children and cycling enthusiasts. The event's physical activity impact was strategically prolonged by creating a "Live Your Own Tour of Flanders" campaign, where the event's cycling routes were made accessible year round. Another successful leveraging strategy aimed at community involvement was the opportunity for local municipalities to bid for the title of "Village of the Tour." This title was used to inspire local organizations in the host city to take ownership of identifying and developing locally relevant initiatives that leverage the Tour of Flanders for community benefits. As a Village of the Tour host, schools and families were used as leverage points to instigate changes in the young children's physical activity behavior, specifically focusing on active participation in cycling. Importantly, this study highlighted the critical role of local communities as vehicles to promote active leverage initiatives that result in tangible social and health benefits.

In one of the few studies that have focused on sport event leverage opportunities in the context of LMICs, Schulenkorf and Edwards (2012) investigated event projects aimed at reconciliation between disparate communities in the ethnically divided Sri Lanka. The authors highlighted that in the context of a war-torn society, social and cultural benefits can best be achieved if event organizers and host communities focus strategically on children as catalysts for change; provide event-related sociocultural opportunities; engage in social, cultural, political, and educational event leverage activities; and combine events with regular sport-based development programs. The final point seems especially important, as the authors predicted that "regularly scheduled sport programs [may] allow for a deepening and intensification of contacts and friendships, while... special events enable an extension of relationships to the wider community" (Schulenkorf \& Edwards, 2012, p. 385).

Overall, the current body of literature suggests that the success of leveraging small-scale, regional, or national sport events for social benefits is determined by a number of factors, including specifying the goal/target for leverage, integrating the leveraging program with the rest of the event planning, involving relevant community stakeholders, and ensuring that the leveraging experience is sustained beyond the duration of the event. Building on these findings and earlier theorizing, the aim of the current study is to contribute to the limited body of literature on how to maximize the potential outcomes of sport events for host communities in LMICs. This is timely given recent arguments by Sherry, Schulenkorf, and Chalip (2015), who suggested that sport events in LMICs provide not only an interesting but also an important context for study, particularly if these events are "funded by international agencies yet delivered by local organizers and volunteers” (p. 3). In this study, we investigate a small-scale community sport event that was implemented in Sāmoa in 2012. The next section provides the geographical context and background information on the event.

\section{Context}

\section{Study Context}

The 10 islands of Sāmoa are located in the southwest Pacific Ocean, with only four of these islands inhabited. Sāmoa has a total population of around 193,000 , out of which $20 \%$ are residing in the capital Apia. Sāmoa is a parliamentary democracy with a Westminster-style Cabinet government; it is a small, fairly liberalized economy, with a gross domestic product (GDP) of around US\$865 million (New Zealand Ministry of Foreign Affairs and Trade, 2017). The country heavily relies on foreign imports, remittances from expatriate Sāmoans, as well as development aid, especially from neighboring Australia and New Zealand. The nation's own economy is largely driven by services (64\% of GDP), especially tourism (around 30\% of GDP), as well as local industries (26\% of GDP) and agriculture (10\% of GDP).

The fa'a Sāmoa, or traditional Sāmoan way, remains a strong force in Sāmoan life and politics. Despite centuries of European influence, Sāmoa has maintained its historical customs as well as social, political, and cultural systems. In particular, 
Sāmoa's culture is centered on the principle of vāfealoa'i, the relationships between people, which has resulted in strong family ties and community networks that are heavily influenced by local chiefs, church leaders, and matais (the holders of family chief titles). Against the background of limited job opportunities and high unemployment rates in the country-particularly for the younger generationstrong social networks and trustful relationships with influential individuals are also important for employment purposes.

Apia is the hub for various sport associations and the majority of organized sport events in the country. Although there is a significant amount of informal and unstructured sport played in rural Sāmoa, sport teams from villages regularly travel to Apia to compete in major competitions. In regards to sport participation and development initiatives, Sāmoa traditionally relies upon assistance from foreign countries to finance programs and events. For example, since the 2011-2012 financial year, the Australian Sports Outreach Program (ASOP) has been targeting funding into Sāmoa—a joint strategy and agreement between AustralianAID and the Australian Sports Commission. The ASOP "aims to increase the capacity of partners (local authorities, development partner agencies and communities) to plan and conduct quality, sport-based activities which contribute to addressing locally identified development priorities” (Australian Sports Commission, 2013, p. 3).

One of the top development priorities on the island is the reduction of life-threatening noncommunicable diseases (NCDs). In short, NCDs include diabetes, cardiovascular diseases, different types of cancer, and depression; they are described as "lifestyle diseases" that result from physical inactivity, high levels of obesity, and diets rich in fat, salt, and sugar [World Health Organization (WHO), 2012]. In 2002, NCDs accounted for 71\% of deaths in the country (WHO, 2005a) - a staggering number that can be explained, however, by the fact that $89 \%$ of Sāmoan women and $85 \%$ of men are classified as overweight or obese (WHO, 2005b). Importantly, childhood overweight and obesity is also a major concern, with $14.3 \%$ of Sāmoan school children affected (Ministry of Health Samoa, 2011). Regrettably, health expenditure is generally focused on the provision of tertiary care services (treatment), leaving fewer funds available for preventive services, including healthy lifestyle programs, sport participation initiatives, and special events aimed at increasing the awareness and the number of activities geared toward reducing NCDrelated problems.

However, in recent years the Sāmoan Ministry of Health has started to collaborate with other governmental departments, nongovernmental organizations (NGOs), religious organizations, and local communities to reverse the NCD epidemic. As a result, a number of targeted initiatives have been implemented, including over 180 community physical activity initiatives across the islands, more than 40 workplace programs run within government and private sectors, and several other physical activity events, such as "National Healthy Lifestyle Week," that have been staged in Apia (Ministry of Health Samoa, 2011). However, what appears to be lacking are any evaluation reports or impact assessments that measure the effects of these initiatives. Moreover, there is limited research investigating the specific sociocultural and managerial aspects of sport programs and events in the country, which seems a missed opportunity for knowledge transfer and the communication of "lessons learned." Against this background, this study presents a sociomanagerial analysis of the Faleata Schools' Just Play (FSJP) Festival. The FSJP Festival is a small-scale sport event orchestrated by the Sāmoan Just Play program, a sport-based development initiative coordinated by the Oceania Football Association and supported by a number of local and international stakeholders (for more information on the wider program, see www.justplayofc.org). In our study, we reflect on specific event management processes and leverage mechanisms that have underpinned the festival and highlight strategies across different areas of leverage that were used to maximize beneficial event outcomes for the local community.

\section{Event Context}

The FSJP Festival is a community event initiative that was jointly organized by the Sāmoan Just Play program, the Sāmoan Football Federation (FFS), and the local communities surrounding the Faleata Sporting Complex in Apia. The festival constituted a full day of social, cultural, and sporting 
activities staged on the premises of the FFS. The day commenced at 8 a.m. with the assembly of all 300 participating children from four local primary and secondary schools. To start the official proceedings, a local church reverend said a prayer, the Sāmoan national anthem was played, and speeches were delivered by the FFS president as well as an occasional guest speaker. These formal activities were followed by traditional dancing performances staged by local children representing their schools and community.

The sporting festival had a predominant focus on football (or soccer) games and interschool competitions, but also included other sporting activities including rugby, netball, and kirikiti-the local and traditional version of cricket played in Sāmoa (for more information on the game and its origins, see Khoo, Schulenkorf, \& Adair, 2014). In addition to sport, the festival also offered cultural activities, educational workshops, and healthrelated awareness sessions that were co-organized by local stakeholders, including the Sāmoan Ministry of Health, the Red Cross, the Sāmoan Victims Support Group, local educators and social workers, as well as community members including elders and volunteers. The nonsporting activities were strategically integrated into the sporting schedule, providing opportunities for nonplaying school groups, parents, and the wider community to attend development sessions throughout the day. All children were also part of an NCD workshop facilitated during lunch time. The festival ended at 6 p.m. after the finals were played and before Sāmoa's national football team entered the main stadium for a training session.

\section{Method}

Our qualitative research study is underpinned by an interpretivist mode of inquiry, which suggests that access to reality can be socially constructed through language, consciousness, and shared meanings (Crotty, 1998; Glesne, 1999; Neuman, 2003). Interpretive research acknowledges that data are analyzed through a process of induction, which means that researchers construct and reconstruct meaning in relation to the research aim based on respondents' realities (Denzin \& Lincoln, 2011). According to Myers (1997), interpretive studies aim to understand the context of a phenomenon through the specific meanings that people assign to it.

To achieve Verstehen, or empathetic understanding, qualitative researchers often apply purposeful sampling as their dominant strategy (Hoepfl, 1997; Patton, 2002; Stark \& Torrance, 2005). In other words, information-rich cases are identified and studied in depth, to achieve a greater understanding of the context and phenomenon under investigation. For this study, the lead researcher conducted 20 semistructured interviews and two focus groups with 14 Sāmoan respondents around the FSJP Festival in May and June 2012. As the investigation aimed to explore and apprehend the sociomanagerial processes behind the festival — and to elucidate people's ideas and recommendations for leveraging and sustaining event benefits for communities-a majority of interview respondents held managerial or organizational roles, including program and festival organizers, Just Play staff, development officers, and teachers (see Table 1 for a detailed overview). At the same time, the focus groups had a strong community focus, which allowed us to examine the perceptions and actual experiences of the "recipients" of the projects. Here, participants included community representatives such as local chiefs, ordinary community members, and volunteers who were able to provide a local perspective on the community engagement and leveraging efforts (see Table 2 for details).

Overall, individual interviews lasted between $20 \mathrm{~min}$ and $1 \mathrm{hr}$, while both focus groups engaged in open discussions about $1.5 \mathrm{hr}$ each. Research questions were based on previous theoretical and empirical research conducted in the context of

Table 1

Interview Respondents

\begin{tabular}{lcl}
\hline Stakeholder Type & Number & \multicolumn{1}{c}{ Gender } \\
\hline Just Play staff & 2 & 1 female, 1 male \\
Festival organizers & 3 & 1 female, 2 male \\
Program coordinators (casual) & 3 & 1 female, 2 male \\
Community representatives & 4 & 1 female, 3 male \\
School teachers & 2 & 1 female, 1 male \\
Volunteers & 3 & 2 female, 1 male \\
Government officials & 2 & 2 male \\
Health expert/nutritionist & 1 & 1 male \\
Total & 20 & 7 female, 13 male \\
\hline
\end{tabular}


Table 2

Focus Group Participants

\begin{tabular}{lcc}
\hline Stakeholder Type & Number & Gender \\
\hline Community representatives & 8 & 2 female, 6 male \\
Volunteers & 4 & 1 female, 3 male \\
Chiefs/Matais & 2 & 2 male \\
Total & 14 & 3 female, 11 male \\
\hline
\end{tabular}

event planning and management (see Chalip, 2006; O’Brien \& Chalip, 2008; Schulenkorf \& Edwards, 2012; Welty Peachey et al., 2015) as well as leverage and sustainability (see Misener, 2015; O’Brien, 2007; Schulenkorf, 2012; Welty Peachey et al., 2015); in particular, they included: Which aspects of the event planning process were the most important to achieve desired outcomes? Which partners did you cooperate with to maximize event benefits? What can be done to sustain positive outcomes beyond the event? What should be done in the future to attract more people and the wider community? Reflecting on this year's event, what would you do differently next time to maximize event leverage efforts?

During all face-to-face discussions, the lead researcher aimed at establishing a trustful relationship with local participants who were encouraged to speak openly about their SFD and program experiences. Formal trust was generated through official documents confirming the intention, purpose, and ethics approval of the research. Informal trust was achieved by establishing rapport with the respondents; in particular, the interviewer commenced discussions with a brief reflection on his positive experiences in the Pacific Islands and previous study engagements in Sāmoa. He also clarified that participation in this study was voluntary and that pseudonyms would be used to anonymize individuals in any documentation resulting from this research. Moreover, after the transcription of interviews, all participants had the opportunity to read their transcripts and rectify any potential mistakes.

Once all data were collected, the authors engaged in a thematic data analysis process that can be described as "working with data, organizing it, breaking it into manageable units, synthesizing it, searching for patterns, discovering what is important and what is to be learned, and deciding what you will tell others” (Bogdan \& Biklen, 1982, p. 145). The computer software package, NVivo 10, was used to support these steps of analysis and assist the researchers in integrating, indexing, and coding the large amount of qualitative data collected. From a process perspective-and in an attempt to further enhance the dependability and credibility of the study - triangulation of measures and research investigators was employed (see Lincoln \& Guba, 1985). As a first step, both authors coded the data independently; if disagreements arose around particular codes or themes, open and honest discussions were held until consensus was reached. Data were then clustered into various leverage areas and while previous literature and theories provided the backdrop for our analysis, they did not dictate coding decisions. Instead, we allowed for relevant areas to emerge from participants' quotes as well as the researchers' direct observations. When presenting our thematic findings, we chose the most representative and rich quotations from our dataset, thus enabling respondents to relay the story behind the data - an approach that has been employed successfully by sport and event management scholars (see Schulenkorf \& Edwards, 2012; Schulenkorf, Sugden, \& Burdsey, 2014; Welty Peachey et al. 2015).

Overall, the structured analysis process employed for this study resulted in a better understanding of relationships between the data and emerging arguments, and allowed for the coding and reconceptualizing of data into five overarching leverage areas: (a) Sociocultural, (b) Participatory, (c) Educational, (d) Health, (e) and Reputational. These five leverage areas are used to structure and guide the findings and discussion section that follows.

\section{Findings and Discussion}

This study set out to empirically investigate leverage opportunities and underpinning managerial processes in the context of community sport events in LMIC settings. In this section, we present and discuss our findings according to the five leverage areas identified from the data. We highlight representative comments and reflections for each area and suggest ways in which event organizers and local communities can maximize beneficial outcomes in the future. 


\section{Sociocultural}

Several interviewees and both focus groups highlighted the opportunity to use the FSJP Festival for sociocultural leverage. In a country where social and cultural elements play a significant role in daily life, the involvement of church leaders and community representatives are important aspects for the staging of locally accepted and widely supported events:

From a management perspective, we had to make sure that Reverend Esera was available to say a prayer in the morning. Also, the words of the football president and the involvement of the local matais were important. If they support your [festival], they will promote it and the community will be behind it. (Event organizer)

This statement suggests that around the event, cultural protocols needed to be followed; however, it also indicates that key individuals such as community or religious leaders are in a position to assist with sociocultural leverage. This finding is in line with Misener's (2015) argument for the role of a catalyst/champion as key to developing leveraging strategies. A catalyst/champion is "well connected and well respected within the community, thus serving a key role in identifying appropriate community partners and initiating action in the local community” (Misener, 2015, p. 145). This definition readily applies to the local reverend in Faleata who-during his opening speech at the festival-built on his status as a local leader to remind people that sport events should be a celebration for all members of the community, including those with a disability. His comment was linked to a local school dancing performance that included two children with a disability:

We purposely decided to include Leilani and Lasalo in the performance. This was a chance to show the other kids that they are part of our team. We also spoke to Reverend Esera beforehand and he praised us for our efforts-even in his opening speech! (Teacher)

From a management perspective, the organizers engaged in a partnership with Sāmoa Special Olympics to maximize opportunities to showcase the talent and special contributions of athletes with a disability. However, more importantly was the close cooperation with the local reverend who engaged in a targeted social leverage and messaging activity that was particularly relevant given the local cultural context. The reverend had started his messaging on social inclusion at the local church service in the week leading up to the event, and he reinforced the message the week following the event. Although this type of "social messaging" may not necessarily work all over the world, it turned out to be a successful approach in a country like Sāmoa, where religious and cultural following is strong and $98 \%$ of the population identifies with the same (Christian) background.

In addition to this spiritual element, the inclusion and showcasing of cultural traditions such as dance and arts and craft provided additional opportunities for sociocultural leverage. Careful planning and community consultation/involvement was needed to guarantee relevant activities; for example, it needed to be clear that dancing was in line with local traditions and that all participating schools would get equal opportunity to showcase their talent. Interestingly, the idea of using arts and craft stalls around the event to achieve economic benefits was controversially discussed; eventually, the organizers followed the community chiefs' recommendation and decided against the inclusion of this "for-profit" element in order to preserve the event's social character. This example highlights the potential clashes among the different areas of event leverage and the importance of a community-centered approach to development (see, for example, Darnell \& Hayhurst, 2011; Schulenkorf, 2012). Furthermore, it directly supports claims by Taks (2013) and Misener (2015) to prioritize local voices in the design and implementation of locally relevant leveraging strategies. We contend that this argument is particularly relevant for small-scale events where local communities are often both the source and the beneficiaries of event outcomes.

\section{Participatory}

Leverage for participation purposes has traditionally seen an external focus, where regular participation in sport clubs or physical activity groups was the intended outcome (Craig \& Bauman, 2014; Weed et al., 2012). In contrast, participatory leverage around the FSJP Festival took a different angle; here, an internal focus aimed at leverage 
for managerial participation-in other words, an increase in active participation in the organizing and delivery of events. For example, the festival offered opportunities to become engaged in voluntary and paid managerial roles on and off the pitch, allowing community members to gain experience useful for future involvement in the Just Play program, other large community projects, or committee roles:

I saw this festival as a practice run. You know, I was able to show the community that I can organize things, that I am a leader in project management. I knew that the chief attended the festival and so I made sure that he could see what I was doing [laughs]. Now he has seen me and maybe he invites me to participate in one of his next events. (Volunteer)

The statement suggests that the event provided an opportunity to showcase managerial talent to a wider audience. In other words, some volunteers aimed to leverage their participation for involvement in future community campaigns and potential employment opportunities. Here, the participation category overlaps with aspects of economic leverage, where financial benefits are sought from an active involvement in an event (see Chalip \& Leyns, 2002; Chalip \& McGuirty, 2004). Against the background of a difficult socioeconomic context in Sāmoa-and a strong reliance on social networks to gain employment-the strategy of using sport events as a vehicle for participation in the workforce seems vital. A Just Play officer stated:

Some of our event volunteers go on to work on the program, but we can only cater for so many. Others find jobs with other sport organizations or they work for local clubs. I can tell you that only the best volunteers are picked and often we are asked for recommendations. There are plenty of people, [but] not many jobs. So, at events like this they can show their abilities and attitude.

As indicated, this finding goes beyond the current theorizing of leveraging sport events for participation. In short, we suggest broadening the concept of participation to include managerial aspects of participation as well as other related nonplaying roles, including participation as officials, coaches, or umpires. Overall, this extended approach will maximize the potential for community members to become actively engaged in the organizing and delivery of future events. Therefore, in the future, it will be important to place a practical and theoretical focus on specific strategies and tactics that help to maximize the potential in this extended area of event leverage, which seems particularly relevant for projects conducted in LMIC settings.

\section{Educational}

The FSJP Festival was also used for educational leverage. Overall, the festival significantly relied on volunteers and casual staff members to support event organization and delivery. Prior to their involvement, all team members received access to event workshops, education sessions, and coaching clinics delivered by Just Play as well as local and/or international management experts. As contractors, the experts provided training courses in project management and all participants were awarded an official certificate upon completion. A casual staff member stated:

The workshops give me the chance to learn [event management] skills. I don't get much money for my work at the festival, but I get free education. All the sessions are great and at the end we receive our certificate. That will all help me in the future.

The statement suggests that volunteers and casual staff members, in particular, viewed the learning components around the festival as a springboard for educational development and the gaining of new skills. Interestingly, at the time of data collection the Sāmoan Ministry of Education, Sports and Culture (MESC) had only played a minimal role in educational leverage activities. Although the Just Play team desired stronger cooperation to place a stronger focus on community learning initiatives, there seemed to be political reasons and power games that prevented the MESC from closer engagement. A Just Play administrator noted:

Here in Sāmoa, everyone protects their own space and money. They all want to "own” programs and if there is already an "owner," they are not interested to come on board. They think they waste their money. So many programs are either supported by the Ministry of Health, or MESC, or an international funder, or Women in Business Foundation, etc. But they never work together. 
In this particular case, Just Play's close relationships with the Ministry of Health and external funders such as the Australian Government seem to have prevented MESC from engaging in joint leveraging activities. This outcome speaks to the difficulty in achieving buy in from all (potential) event stakeholders, and also reinforces Misener's (2015) argument for the importance of the policy environment and how this can enable or constrain the leveraging of an event. Moreover, in the case of externally funded development projects, local power dynamics and the pressure to deliver development outcomes present significant factors that impact the willingness to cooperate, and often, organizations will only contribute if they can claim and sell project outcomes as their own exclusive achievements (see Khoo et al., 2014; Schulenkorf \& Edwards, 2012). For the FSJP Festival, it meant that significant opportunities to maximize educational and health-related outcomes remained unused. Therefore, the implication for event managers and local communities is to assess the current policy environment-particularly regarding existing relationships among various organizations - and to ensure that these enable, rather than constrain, an event's leverage opportunities.

\section{Health}

As a strong partner of Just Play and FFS, the Ministry of Health engaged in a number of targeted event leverage activities focused on promoting healthy lifestyles and overall community wellbeing. Around the sporting ground, small tents and information booths were set up and populated by groups of children and their teachers during nonplaying time. Here, information talks and leaflets on NCD prevention, healthy eating, and the benefits of regular physical activity were provided; moreover, the event organizers aimed to go beyond the participating school children and also offer information about healthy lifestyles to accompanying parents and the wider community:

The info tents were a good idea and the kids loved the interactive part. Remember where Sam [health expert] used his laptop to show how fat people's bellies can grow if they eat the wrong food? The kids couldn't believe it! They also liked how they were praised as a good example for health. You know, that they play football and exercise in sport. When Sam showed them how the big belly gets smaller, they all loved it. They were so happy. (Just Play staff member)

Although the children benefited from the close interaction with the health expert at the information tent, it was observed that there were hardly any adults frequenting the area. Arguably, this had to do with a number of well-intended but badly executed promotion campaigns in the lead up to the festival. For example, in an attempt to achieve health-related leverage, promotional flyers were jointly produced and distributed by Just Play and the Ministry of Health; furthermore, billboards were put up in front of the FFS headquarters and the Ministry ground. However, there were mixed reactions to this strategy, as noted by a community representative:

I think the billboards were a waste of time. No normal people ever saw them, only the ones that went to the football ground anyway. They should have put another billboard up right in the middle of our community where people could actually see it. Also, the flyers were useless - they did not even state the exact time of information sessions etc. I do not think people felt attracted to come.

Although this community member was largely critical of the particular approach used to promote and leverage the festival, he remained confident that health-related leverage can and should be achieved. In the context of a society that shows remarkably high NCD rates, he argues that more needs to be done to change the status quo:

I mean, at least Just Play tries to do something to improve people's health. There are so many sport programs out here and none of them link with the health sector. With all our obesity issues, I wonder why that's the case?! Really, every sport program should have a specific health aspect to it; otherwise, we are wasting our time. So many programs focus on social issues only. I mean, come on ... . social connections in Sāmoa are not a big issue, clearly! Let's get real and put our energy towards the things that matter. Inform people about the consequences of NCDs in a way that is more "hardcore" and shocking to them and also provide sport programs that are accessible for all people, also the big ones!

This statement suggests that numerous NGOs and development agencies in Sāmoa seem to 
ignore the "obese elephant in the room.” This claim is backed up by recent research, which found that despite the significant number of physical activity opportunities provided across the Pacific Island region, there remains a lack of targeted, relevant, and meaningful health activities-particularly for overweight and obese members of the community (see Siefken, MacNiven, Schofield, Bauman, \& Waqanivalu, 2012). Applied to the FSJP Festival, it seems that an important first step has been made (i.e., including health components into the program). However, the second step (i.e., targeted projects or activities for a problem audience) was only partly realized; in other words, the activities attracted the children, but they are only one part of the problem. Unfortunately, organizers and stakeholders were unable to attract parents and the wider community to the healthy lifestyle information sessions and workshops.

Here, something can be learned from Derom and VanWynsberghe's (2015) analysis of leveraging the Tour of Flanders cycling event; in particular, the tour organizers developed a targeted set of initiatives, each aimed at particular individuals in the host community, including children, recreational, as well as competitive cyclists. Importantly, community members and organizations representing the "Village of the Tour" were directly involved in developing locally relevant leveraging initiatives, such as establishing ongoing access to the Tour of Flanders cycling routes for use by the wider community. Such cooperative involvement allowed the community to take "ownership" of programs that were most beneficial for them, which in turn led to greater community support and participation. The implication for event organizers and those involved in the development of leverage initiatives is that strategic planning, active community involvement, and clearly targeted initiatives need to underpin all event management processes.

\section{Reputational}

The reputation of the event organizer-and also that of the local community-can be considered both a source and a beneficiary of event leverage campaigns. Firstly, existing reputational capital may be used and leveraged for marketing and promotion purposes, as participants and attendees may be attracted by the organizer's perceived standing. Secondly, a successful event has the potential to add to reputational capital, which in turn may be used to leverage other programs or events on offer. One of the local volunteers explained:

Many people came to the festival because Just Play and AusAid were running it. They have a good image and everyone knows it's going to be a good event. If it was yet another event done by MESC, I don't think many people would have come. They never do anything exciting and different.

Particularly in a small island context, the reputation of an event organizer-and its supporters-is a critical factor for success. Moreover, in LMIC settings where dozens of development agencies and NGOs are present, people realize very quickly which programs are well run and supported, and which ones lack professional expertise and/or integrity (see e.g., Schulenkorf \& Edwards, 2012; Schulenkorf, Thomson, \& Schlenker, 2011). A similar argument can be made for the reputational capital of a particular social group, which may be able to benefit from its image as an "event community." A casual staff member suggested:

The Faleata community has been known for its ability to run events. Every time a new event is staged in this place, people know it is going to be great! People talk about the "festival village" and they like to come along. The close partnership with Just Play and the football federation helps a lot, too.

The reputation of being a "festival village" is something that the Faleata community can leverage off in the future. Moreover, the staff member's statement demonstrates how in this case, the Faleata community is both the source and beneficiary of reputational capital—an asset that can and should be leveraged strategically for future event promotion campaigns and media engagements. From a theoretical perspective, the reputation of an event organizer and/or an event community can therefore provide the seed capital that may be leveraged to the strategic advancement of sociocultural, participatory, and economic benefits. In other words, the events themselves are not the key factor in this process (see O'Brien, 2006); instead, it is the reputation that attracts people to participate, 
engage, attend, and support festivals organized by the "event community."

\section{Limitations}

When using SFD programs and special events as vehicles to contribute to community development, it is important to consider the often complex historical, cultural, and sociopolitical context of the country and society in question. As previously discussed, the fa'a Sāmoa remains a strong force in everyday Sāmoan life as well as community politics and hence, as researchers we had to follow a number of cultural protocols. Some of these resulted in benefits for our research as access to influential local chiefs, church leaders, and matais was facilitated and supported throughout our study; on the other hand, we must acknowledge the limitations of our investigation, including the purposeful sampling strategy employed. In particular, given the Sāmoan cultural setting that is strongly influenced by a hierarchical, largely male-dominated social system, the snowball approach that underpinned our work resulted in a potentially skewed representation of real community life. In particular, out of the 20 individuals that participated in our faceto-face interviews, only one third were females; moreover, the two focus groups were dominated by (often older) men while young females were significantly underrepresented in our sample.

Although overall, a smaller sample size is not uncommon for context-specific, in-depth qualitative investigations, we acknowledge that followup research with a larger population-as well as a stronger focus on women-will contribute to establishing a more balanced picture; moreover, it will allow the inclusion of different and "fresh" ideas in regards to opportunities and limitations of using events as a vehicle for community development. Therefore, we encourage researchers to build on the foundations laid by this study and conduct all-inclusive research in the future, with a specific focus on accessing and utilizing local female voices in the process.

\section{Conclusions and Further Research}

Sport events have increasingly been used as a vehicle for achieving different community development outcomes. In contrast to large-scale and mega-events that are merely required to "consider" community impacts in their bid documents and legacy planning, small-scale events often present a purposeful attempt to improve the quality of life of the host community. Against this background, our study from the Pacific Island nation of Sāmoa presented empirical findings from a community festival staged in a LMIC setting, an area that has so far been neglected in the sport event management literature. Our investigation highlighted a number of critical event management processes and leverage mechanisms that have underpinned the FSJP Festival, and it has identified different strategies for maximizing beneficial event outcomes. In particular, we have presented and extended findings related to the areas of sociocultural and participatory event leverage, and have presented new areas that seem particularly relevant in the context of community development in LMIC settings, including educational, health-related, and reputational leverage.

To achieve social and cultural leverage, smallscale event organizers have to connect the event with key individuals and institutions that are highly respected in the community. For example, any event promotion campaign in a country like Sāmoa is likely to have a greater and more sustained impact if it is supported by church leaders as well as local chiefs and matais. The respect and integration of local traditions and customs seem particularly relevant in a setting like the Pacific Islands, where family roots, religious following, and community ties hold significant value in people's daily lives.

In terms of participatory leverage, our study presents a new angle that event managers and local communities should take into consideration. The area of participatory event leverage has previously focused on the improvement of regular participation and involvement in sport clubs or groups; however, our findings revealed a new dimension of participation: participation in the management and delivery of projects, and the opportunities to leverage managerial participation for socioeconomic benefits. In particular, the opportunity to showcase managerial talent as a support worker or event volunteer was seen as a platform for future employment within and beyond the sport event sector. In LMIC settings-especially those with tight 
social networks and structures-this strategy is of particular importance, as it allows individuals to "perform" in front of influential community leaders. Overall, this finding has implications for event managers in their approach toward recruiting volunteers and marketing casual positions. It also has theoretical implications, widening our understanding of what leveraging for participation might look like in different community settings.

In line with this, the prospect for educational leverage around small-scale events is significant; in fact, given more specific and targeted development opportunities for local staff and volunteers, small-scale events may provide better opportunities for educational leverage than large-scale projects. In support of the wider goal of achieving sustainable community development in LMICs-and potential independence from external funders - the cooperation between event organizers and education providers seems critical. At the FSJP Festival, such cooperation resulted in joint workshops, training sessions, and coaching clinics between Just Play and local ministries that not only benefited individual participants, but also the wider Just Play sport development program and its (casual and permanent) workforce.

As a sports program and social development provider, Just Play was able to gain reputational capital from its involvement in the event. In turn, the organization leveraged this capital throughout its marketing campaigns and used its status as a respected institution to attract additional participants, attendees, and volunteers to the event. It seems that in a positive perpetual process, the provision of exciting and well-organized events leads to additional reputational capital that in turn adds to the image of the organizer, who will attract more attendees at the next event. Similarly, the local Faleata community was able to build on its reputation as a "hub" for sport projects and its reputation as a "festival village." Overall, we propose that the nurturing and leveraging of reputational capital is particularly important in LMICs, where hundreds of NGOs and development agencies offer projects to the community with varying levels of relevance, local buy in, support, and-ultimately—success.

Finally, our research suggests that for any sport event project in the Pacific Islands, a strong connection to health-related leverage should be secured.
Given an overweight population and staggering obesity rates - for adults, children, and teenagers the absence of health-related messaging and promotion for active engagement beyond the event would present a significant opportunity lost. Importantly, this messaging should not only be directed at participating children at the sport event, but also at their parents and the wider, currently nonactive community. In other words, how to best achieve buy in from those currently not engaged in sport and regular physical activity remains an important question to be answered in future research. In fact, a study on this topic would be one of the first to make the important and long-required step toward addressing the "obese elephant in the room." We encourage researchers from different academic backgrounds-including sport and event management, community development, sociology, health science, cultural studies, and so on-to further advance research in this area. We are confident that our study will provide a starting point for those academics as well as event organizers and policymakers in their attempt to provide active, culturally relevant, and overall meaningful sport event experiences for disadvantaged communities.

\section{References}

Australian Sports Commission. (2013). Australian sport outreach program. Retrieved from https://www.clearinghouse forsport.gov.au/_data/assets/pdf_file/0011/636752/ Australian_Sport_Outreach_Program_CABOS_position_ paper.pdf

Bogdan, R. C., \& Biklen, S. K. (1982). Qualitative research for education: An introduction to theory and methods. Boston, MA: Allyn \& Bacon.

Brown, A., \& Massey, J. (2001). Literature review: The impact of major sporting events. London: UK Sport.

Chalip, L. (2004). Beyond impact: A general model for host community event leverage. In B. Ritchie \& D. Adair (Eds.), Sport tourism: Interrelationships, impacts and issues (pp. 226-252). Clevedon, UK: Channel View.

Chalip, L. (2006). Towards social leverage of sport events. Journal of Sport \& Tourism, 11, 109-127.

Chalip, L., \& Leyns, A. (2002). Local business leveraging of a sport event: Managing an event for economic benefit. Journal of Sport Management, 16, 132-158.

Chalip, L., \& McGuirty, J. (2004). Bundling sport events with the host destination. Journal of Sport \& Tourism, 9, 267-282.

Craig, C. L., \& Bauman, A. (2014). The impact of the Vancouver Winter Olympics on population level physical activity and sport participation among Canadian children and adolescents: Population based study. International 
Journal of Behavioral Nutrition and Physical Activity, 11(1), 107.

Crotty, M. (1998). The foundations of social research. Sydney, Australia: Allen \& Unwin.

Darnell, S. C., \& Hayhurst, L. (2011). Sport for decolonization: Exploring a new praxis of sport for development. Progress in Development Studies, 11, 183-196.

Denzin, N. K., \& Lincoln, Y. S. (2011). The SAGE handbook of qualitative research (4th ed.). Thousand Oaks, CA: Sage.

Derom, I., \& VanWynsberghe, R. (2015). Extending the benefits of leveraging cycling events: Evidence from the Tour of Flanders. European Sport Management Quarterly, 15, 1-21.

Dimmock, K., \& Tiyce, M. (2001). Festivals and events: Celebrating special interest tourism. In N. Douglas \& R. Derrett (Eds.), Special interest tourism (pp. 355-383). Milton, Australia: Wiley.

Glesne, C. (1999). Meeting qualitative inquiry. In C. Glesne \& A. Peshkin (Eds.), Becoming qualitative researchers: An introduction (2nd ed., pp. 1-17). New York: Longman.

Hoepfl, M. C. (1997). Choosing qualitative research: A primer for technology education researchers. Journal of Technology Education, 9(1), 47-63.

Karadakis, K., Kaplanidou, K., \& Karlis, G. (2010). Event leveraging of mega sport events: A SWOT analysis approach. International Journal of Event and Festival Management, 1, 170-185.

Khoo, C., Schulenkorf, N., \& Adair, D. (2014). The opportunities and challenges of using cricket as a sport-fordevelopment tool in Samoa. Cosmopolitan Civil Societies: An Interdisciplinary Journal, 6, 76-102.

Lane, A., Murphy, N., \& Bauman, A. (2013). An effort to "leverage" the effect of participation in a mass event on physical activity. Health Promotion International, 30, 542-551.

Lincoln, Y. S., \& Guba, E. G. (1985). Naturalistic inquiry. Beverly Hills, CA: Sage Publications.

Ministry of Health Samoa. (2011). Article 4 healthy lifestyle week. Apia, Samoa: Author.

Misener, L. (2015). Leveraging parasport events for community participation: Development of a theoretical framework. European Sport Management Quarterly, 15, 132-153.

Misener, L., \& Mason, D. S. (2006). Creating community networks: Can sporting events offer meaningful sources of social capital? Managing Leisure, 11, 39-56.

Misener, L., \& Mason, D. S. (2008). Urban regimes and the sporting events agenda: A cross national comparison of civic development strategies. Journal of Sport Management, 22, 603-627.

Misener, L., McGillivray, D., Gayle, M., \& Legg, D. (2015). Leveraging parasport events for sustainable community participation: The Glasgow 2014 Commonwealth Games. Annals of Leisure Research, 18, 450-469.

Misener, L., Taks, M., Chalip, L., \& Green, C. B. (2015). The elusive "trickle-down effect" of sport events: Assumptions and missed opportunities. Managing Sport and Leisure, 20, 135-156.
Myers, M. D. (1997). Qualitative research in information systems. MIS Quarterly, 21, 241-242.

Neuman, W. L. (2003). Social research methods: Qualitative and quantitative approaches (5th ed.). Boston, MA: Allyn and Bacon.

New Zealand Ministry of Foreign Affairs and Trade. (2017). Samoa. Retrieved from https://www.mfat.govt.nz/en/ countries-and-regions/pacific/samoa/

O’Brien, D. (2006). Event business leveraging: The Sydney 2000 Olympic Games. Annals of Tourism Research, 33, 240-261.

O’Brien, D. (2007). Points of leverage: Maximizing host community benefit from a regional surfing festival. European Sport Management Quarterly, 7, 141-165.

O’Brien, D., \& Chalip, L. (2007). Executive training exercise in sport event leverage. International Journal of Culture, Tourism and Hospitality Research, 1, 296-304.

O’Brien, D., \& Chalip, L. (2008). Sport events and strategic leveraging: Pushing towards the triple bottom line. In A. Woodside \& D. Martin (Eds.), Tourism management: Analysis, behaviour and strategy (pp. 318-338). Cambridge, MA: CABI.

Patton, M. Q. (2002). Qualitative evaluation and research methods (3rd ed.). Thousand Oaks, CA: Sage.

Preuss, H., \& Solberg, H. A. (2006). Attracting major sporting events: The role of local residents. European Sport Management Quarterly, 6, 391-411.

Ritchie, J. (1984). Assessing the impact of Hallmark events: Conceptual and research issues. Journal of Travel Research, 22, 2-11.

Schulenkorf, N. (2010). Bridging the divide: The role of sport events in contributing to social development between disparate communities. European Journal of Tourism Research, 3, 127-131.

Schulenkorf, N. (2012). Sustainable community development through sport and events: A conceptual framework for sport-for-development projects. Sport Management Review, 15, 1-12.

Schulenkorf, N. (2013). Sport-for-development events and social capital building: A critical analysis of experiences from Sri Lanka. Journal of Sport for Development, 1(1), 25-36.

Schulenkorf, N., \& Edwards, D. (2012). Maximizing positive social impacts: Strategies for sustaining and leveraging the benefits of intercommunity sport events in divided societies. Journal of Sport Management, 26, 379-390.

Schulenkorf, N., Schlenker, K., \& Thomson, A. (2017). Strategic leveraging of large-scale and mega-events. In S. Frawley (Ed.), Managing sport mega-events (pp. 139-149). Abingdon, UK: Routledge.

Schulenkorf, N., Sugden, J., \& Burdsey, D. (2014). Sport for development and peace as contested terrain: Place, community, ownership. International Journal of Sport Policy, 6(3), 371-378.

Schulenkorf, N., Thomson, A., \& Schlenker, K. (2011). Intercommunity sport events: Vehicles and catalysts for social capital in divided societies. Event Management, 15, 105-119. 
Sherry, E., Schulenkorf, N., \& Chalip, L. (2015). Managing sport for social change: The state of play. Sport Management Review, 18, 1-5.

Siefken, K., MacNiven, R., Schofield, G., Bauman, A., \& Waqanivalu, T. (2012). A stocktake of physical activity programs in the Pacific Islands. Health Promotion International, 27, 197-207.

Smith, A. (2009). Spreading the positive effects of major events to peripheral areas. Journal of Policy Research in Tourism, Leisure and Events, 1, 231-246.

Smith, A. (2012). Events and urban regeneration: The strategic use of events to revitalise cities. New York: Routledge.

Spaaij, R., \& Schulenkorf, N. (2014). Cultivating safe space: Lessons for sport-for-development projects and events. Journal of Sport Management, 28(6), 633-645.

Stark, S., \& Torrance, H. (2005). Case study. In B. Somekh \& C. Lewin (Eds.), Research methods in the social sciences (pp. 33-40). Thousand Oaks, CA: Sage.

Taks, M. (2013). Social sustainability of non-mega sport events in a global world. European Journal for Sport and Society, 10, 121-141.

Taks, M., Green, C. B., Misener, L., \& Chalip, L. (2014). Evaluating sport development outcomes: The case of a medium-sized international sport event. European Sport Management Quarterly, 14, 213-237.

Taks, M., Misener, L., Chalip, L., \& Green., B. C. (2013). Leveraging sport events for participation. Canadian Journal of Social Research, 3, 12-23.
Weed, M., Coren, E., \& Fiore, J. (2009). A systematic review of the evidence base for developing a physical activity, sport and health legacy from the London 2012 Olympic and Paralympic Games. Canterbury, UK: Canterbury Christ Church University, Centre for Sport, Physical Education \& Activity Research.

Weed, M., Coren, E., Fiore, J., Wellard, I., Mansfield, L., Chatziefstathiou, D., \& Dowse, S. (2012). Developing a physical activity legacy from the London 2012 Olympic and Paralympic Games: A policy-led systematic review. Perspectives in Public Health, 132, 75-80.

Welty Peachey, J., Borland, J., Lobpries, J., \& Cohen, A. (2015). Managing impact: Leveraging sacred spaces and community celebration to maximize social capital at a sport-fordevelopment event. Sport Management Review, 18, 86-98.

World Health Organization. (2012). World health statistics 2012. Geneva, Switzerland: Author.

World Health Organization. (2005a). Facing the facts: The impact of chronic disease in the Western Pacific. Geneva, Switzerland: Author.

World Health Organization. (2005b). Preventing chronic diseases: A vital investment. Geneva, Switzerland: Author.

Ziakas, V. (2014). Planning and leveraging event portfolios: Towards a holistic theory. Journal of Hospitality Marketing \& Management, 23, 327-356.

Ziakas, V. (2015). For the benefit of all? Developing a critical perspective in mega-event leverage. Leisure Studies, 34, 689-702. 